\title{
Surgical management of large angle congenital esotropia
}

\author{
LEONARD B NELSON,' JOSEPH H CALHOUN,' JOHN W SIMON,' \\ THOMAS WILSON,' AND ROBISON D HARLEY'
}

From the 'Pediatric Ophthalmology Services of Wills Eye Hospital, Philadelphia, Pennsylvania, and $^{2}$ Albany Medical College, Albany, New York

SUMMARY Ninety-seven patients with congenital esotropia with deviations of 50 prism dioptres or greater underwent large $(6$ and $7 \mathrm{~mm})$ bimedial rectus recessions. The overall success rate with one operation was $83 \cdot 5 \%$. Judgment of final alignment was made at the last follow-up examination, six to 61 months (average 23.4 months) postoperatively. Large bimedial rectus recessions for congenital esotropia are an effective surgical treatment which does not significantly alter adduction.

The best surgical treatment of large angle congenital esotropia continues to be controversial. Success rates ranging from 40 to $80 \%$ have been described with a variety of surgical techniques. ${ }^{1-8}$ Traditionally the maximum recession of the medial recti has been approximately $5 \mathrm{~mm}$. $^{7}$ Several investigators have successfully corrected large angle esotropia with bimedial rectus recessions in excess of the traditional $5 \mathrm{~mm}$. ${ }^{91}$ Mittleman and Folk have presented favourable results following re-recession of the medial rectus $13.5 \mathrm{~mm}$ from the limbus for undercorrected esotropia."

In a preliminary report we showed a $91 \%$ success rate with 6 or $7 \mathrm{~mm}$ bimedial rectus recessions in 45 congenital esotropes with deviations of 50 prism dioptres or greater. ${ }^{12}$ Judgment of final alignment was made six weeks postoperatively, with an average follow-up of 13 months. This report presents the long term follow-up of 6 and $7 \mathrm{~mm}$ bimedial recessions for the treatment of large angle congenital esotropia.

\section{Material and methods}

The records of 321 patients with congenital esotropia who underwent surgery at the Pediatric Ophthalmology Service of Wills Eye Hospital between 1979 and 1985 and 136 patients from Albany Medical College between 1981 and 1985 were reviewed.

Correspondence to Leonard B Nelson, MD, Wills Eye Hospital, Pediatric Ophthalmology Service, 9th and Walnut Streets, Philadelphia, PA 19107, USA.
Ninety-seven patients met the criteria for inclusion in this study, which were as follows: (1) constant esotropia present by 6 months of age by history and documented by one of the authors by 1 year of age; (2) preoperative deviation of 50 prism dioptres or greater; (3) alternation of fixation; (4) age of initial operation 2 years or younger; (5) no overt evidence of central nervous system abnormalities or organic eye disease; and (6) follow-up of six months or more.

Cycloplegic refraction with $1 \%$ cycloplentolate, and in some cases $1 \%$ atropine, was performed in all cases. Patients in whom the spherical equivalent was greater than +3.00 dioptres were fitted with spectacles. If the hyperopic correction reduced the esotropia to less than 50 prism dioptres, the patient was eliminated from the study.

Deviations were evaluated by the Hirschberg or Krimsky methods (base out prism in front of each eye) or by the prism and cover test when possible.

All patients underwent bimedial rectus recessions of 6 or $7 \mathrm{~mm}$ by the Parks cul-de-sac approach. For this study an alignment measured between orthophoria and less than 10 prism dioptres of esotropia was considered a success. For the purposes of data analysis the measurement obtained at the last follow-up visit (six months or greater) was used as the final alignment except in those patients subsequently requiring reoperation. In patients reoperated upon the alignment obtained before the second operation was used as the final result from the first operation. If a recurrent esotropia developed, full cycloplegic hyperopic correction of +1.50 dioptres or greater 
was prescribed. For these patients final ocular alignment was recorded with their spectacles.

\section{Results}

Eighty-eight patients had deviations in the range 50 to 70 prism dioptres and underwent bimedial rectus recessions of $6 \mathrm{~mm}$. The remaining nine patients had deviations in excess of 70 prism dioptres and had bimedial rectus recessions of $7 \mathrm{~mm}$. The average deviation in the $6 \mathrm{~mm}$ group was 58.2 prism dioptres of esotropia and the average for the $7 \mathrm{~mm}$ group was 75 prism dioptres. The ages at the initial surgery ranged from 4 months to 24 months (average 12.2 months) for the $6 \mathrm{~mm}$ group and 6 months to 20 months (average 9.9 months) for the $7 \mathrm{~mm}$ group. Refractive errors ranged from -4.75 to +4.50 dioptres (average 1.68 dioptres) for the $6 \mathrm{~mm}$ group, and +0.25 to +3.00 dioptres (average +1.86 dioptres) for the $7 \mathrm{~mm}$ group (Table 1). Follow-up ranged from six months to 61 months, average 23.3 months, for the $6 \mathrm{~mm}$ group, and ranged from seven months to 48 months, average 23.8 months, for the $7 \mathrm{~mm}$ group.

Of the 88 patients who underwent $6 \mathrm{~mm}$ recessions $73(83 \%)$ had ocular alignment between orthophoria and 10 prism dioptres of esotropia at the last followup visit (six months or greater). Four of the 73 patients redeveloped esotropia of 15 prism dioptres or greater, which was corrected with hyperopic spectacles averaging 3.44 dioptres. The esotropia redeveloped on average 21.5 months after the initial surgery.

Thirteen patients in the $6 \mathrm{~mm}$ group required a second operation for esotropia at an average interval of 11.2 months after the first surgery. Five of the 13 patients were initially controlled with a hyperopic correction before the condition decompensated, requiring surgery at an average interval of 22.6 months after the first surgery. Two patients in the 6 $\mathrm{mm}$ group developed a consecutive exotropia at six months and 18 months following the initial surgery for esotropia. Neither patient had developed amblyopia.

Table 1 Summary of clinical data

\begin{tabular}{lcc}
\hline & \multicolumn{2}{c}{ Bimedial rectus recessions } \\
\cline { 2 - 3 } & 6 mm group & 7 mm group \\
\hline Average deviation (PD) & $58 \cdot 2$ & 75 \\
Average age (mon) & $12 \cdot 2$ & $9 \cdot 9$ \\
Average refraction (D) & $+1 \cdot 68$ & $1 \cdot 86$ \\
Success rate & $83 \%$ & $88 \cdot 8 \%$ \\
Average follow-up (mon) & $23 \cdot 3$ & $23 \cdot 8$ \\
\hline
\end{tabular}

$\mathrm{PD}=$ prism dioptre. $\mathrm{D}=$ dioptre. $\mathrm{Mon}=$ months.
Eight of nine patients $(88.8 \%)$ in the $7 \mathrm{~mm}$ group had a successful surgical result. Only one of the nine patients in this group required a second operation for esotropia at 28 months after the first surgery. One additional patient redeveloped esotropia of greater than 15 prism dioptres at 30 months following the initial surgery, which was corrected with $+2 \cdot 50$ dioptre spectacles. None of the patients in this group developed a consecutive exotropia. Overall $83.5 \%$ of both groups combined were successfully aligned. In addition no limitation of convergence or adduction was noted in any of the patients.

\section{Discussion}

The correction of congenital esotropia has been attempted by a variety of surgical techniques. Proponents of two-muscle surgery advocate as the initial procedure either symmetrical bimedial rectus recession or monocular medial rectus recession combined with lateral rectus resection regardless of the size of the preoperative deviation. ${ }^{213}$ Further surgery, either bilateral rectus resections or medial rectus recession and lateral rectus resection on the fellow eye, is performed if the patient needs additional surgery. In the past surgeons favouring bimedial rectus recessions for congenital esotropia have encountered an unacceptable incidence of undercorrections in patients with large deviations. For this reason many have turned to three- and fourmuscle surgery as an initial procedure..$^{35 \times 14} 15$

Ing and coworkers reported a success rate for bimedial rectus recession of only $30 \%$ in 40 patients with esotropia measuring 50 prism dioptres or greater.' Although the authors did not specifically indicate how much medial rectus recession was performed, in 1966, when the paper was published, it would be reasonable to assume the maximum recession was $5 \mathrm{~mm}$.

Helveston and colleagues reported a $72 \%$ success rate for congenital esotropia using graded bimedial rectus recession (maximum recession of $5.5 \mathrm{~mm}$ ) with the measurement performed from the limbus, combined with recession of conjunctiva and Tenon's capsule. ${ }^{4}$ However, the average preoperative deviation was only 38.3 prism dioptres, and assessment of final alignment was made six weeks postoperatively. More recently they described an $82 \%$ success rate using a similar recession technique with a five-month to seven-year follow-up. ${ }^{6}$ In this study $63.9 \%$ of the patients had a preoperative esotropia of 40 prism dioptres or less.

Kushner and Morton recently reported an $84 \%$ success rate for congenital esotropia with preoperative deviations of 35 prism dioptres or greater, assessed six months postoperatively, using non- 
graded bimedial recessions measured from the limbus.' The medial recti were recessed so that the distance from the corneoscleral limbus to the recessed muscle equaled $10.5 \mathrm{~mm}$. Although the average preoperative deviation was 53 prism dioptres, $35.9 \%$ of the patients had a deviation less than 50 prism dioptres with $15.4 \%$ having a deviation of 35 prism dioptres.

In 45 congenital esotropes with deviations of 50 prism dioptres or greater we reported a $91 \%$ success rate using large $(6$ and $7 \mathrm{~mm})$ bimedial recessions. However, judgment of final alignment was made six weeks postoperatively. ${ }^{12}$

von Noorden and coworkers performed a monocular recess-resect operation on 50 congenital esotropes with a $42 \%$ success rate after one operation ${ }^{2} ; 40 \%$ of the patients had a preoperative deviation of less than 40 prism dioptres. The maximum medial rectus recession performed, although not stated in the paper published in 1972 , would presumably have been $5 \mathrm{~mm}$.

The alternative approach to the treatment of congenital esotropia with surgery on three or four of the horizontal rectus muscles has been reported by several investigators. Foster and coworkers described a $79 \%$ success rate with a $5 \cdot 19$ years' average follow-up with one operation using this approach. ${ }^{3}$ However, $67.6 \%$ of their patients had preoperative deviations of less than 50 prism dioptres and $38.2 \%$ had 30 prism dioptres of esotropia or less. Lee and Dyer reviewed 36 congenital esotropes who underwent bimedial rectus recessions and bilateral rectus resections with a $61 \%$ success rate. In their report $83.3 \%$ of the patients had preoperative deviations of 40 prism dioptres or less.

Hirsch and Scott studied 107 congenital esotropes with deviations of 50 prism dioptres or greater in which 57 had a bimedial rectus recession, two had monocular resection-recession, and 48 had three- or four-horizontal-muscle surgery. ${ }^{15}$ The success rate for the two-muscle surgery was $37 \cdot 3 \%$ compared with $64.5 \%$ for the three- or four-muscle procedure. No mention is made about how much medial rectus recession was performed.

Helveston and coworkers suggested that undercorrected esotropia or large consecutive exotropia requiring further surgery was obvious soon after the initial operation. ${ }^{6}$ Recently Bateman and coworkers used computer based discriminant analysis to study the results of congenital esotropia surgery. ${ }^{16}$ They discovered that the preoperative deviation, amount of medial rectus recession, and the interval between the onset of the esotropia and surgery were all statistically significant predictive variables for the surgical outcome six weeks postoperatively. In addition they found that only the postoperative deviation at six weeks was predictive of the long term deviation.

We found that for the 13 patients in the $6 \mathrm{~mm}$ group who required a second operation for esotropia the average interval was 11.2 months after the first surgery. Five of the 13 patients required further surgery at an average interval of 22.6 months. In addition the two patients with a consecutive exotropia developed the deviation at six months and 18 months.

Freeley and coworkers reported on a group of patients with congenital esotropia who were surgically aligned prior to 18 months of age. ${ }^{17}$ They found that $28 \%$ of these patients later redeveloped esotropia, with an average time of onset at 14 months postoperatively. $78 \%$ of this group were corrected with hyperopic spectacles. Five patients in our study fell into this category, and the eyes were straightened with hyperopic spectacles averaging $+3 \cdot 25$ dioptres. The esotropia redeveloped an average of 23.6 months after the initial surgery.

Hess and Calhoun were early proponents of bimedial rectus recessions in excess of the traditional $5 \mathrm{~mm}$ in patients with large angle esotropia. ${ }^{9}$ They reported 30 patients ranging in age from 5 months to 12 years, with an average age of 4 years, who underwent graded bimedial rectus recessions of 6 to $8 \mathrm{~mm} .84 \%$ of the patients in the $6 \mathrm{~mm}$ group (average preoperative deviation 57 prism dioptres) and $60 \%$ in the $7 \mathrm{~mm}$ group (average preoperative deviation 78 prism dioptres) were within 10 prism dioptres of orthophoria following the initial procedure. The one patient who had $8 \mathrm{~mm}$ recessions for an esotropia of 90 prism dioptres was undercorrected. Prieto-Diaz, who was also an early advocate of large bimedial rectus recessions for congenital esotropia, reported that slightly over $80 \%$ of his 85 patients had successful realignment which remained stable over a three-year follow-up period. ${ }^{10}$

Our overall success rate of $83.5 \%$ for the $6 \mathrm{~mm}$ and $7 \mathrm{~mm}$ groups corroborates the experience of PrietoDiaz." Although our results are similar to those of Kushner and Morton ${ }^{7}$ and Helveston and coworkers, ${ }^{6}$ our series included only congenital esotropes of 50 prism dioptres.

We have found that bimedial rectus recessions of 6 and $7 \mathrm{~mm}$, although larger than the conventional maximum, do not result in limitation of convergence or adduction. Avoiding surgery on additional muscles saves anaesthesia time and minimises potential surgical complications. Our overall success rate of $83.5 \%$ suggests that patients with large angle congenital esotropia can be effectively aligned with graded two-muscle surgery and that this postoperative alignment is generally stable over an extended follow-up period. We therefore recommend large 
bimedial rectus recessions as the initial surgical management for this condition, recessing each medial rectus $6 \mathrm{~mm}$ for 50 to 70 prism dioptres of esotropia and $7 \mathrm{~mm}$ for greater than 70 prism dioptres.

This work was supported in part by a grant from Fight for Sight, Inc, New York, to the Fight for Sight Children's Eye Center of Wills Eye Hospital, Philadelphia, Pennsylvania, by the National Institute of Health, National Eye Institute Training Grant EY070370, and an unrestricted grant from Research to Prevent Blindness.

\section{References}

1 Ing M, Costenbader FD, Parks MM, Albert DG. Early surgery for congenital esotropia. Am J Ophthalmol 1966; 61: 1419-27.

2 von Noorden GK, Isaza A, Parks ME. Surgical treatment of congenital esotropia. Ophthalmology (Rochester) 1972; 76: 1465-78.

3 Foster RS, Paul TO, Jampolsky A. Management of infantile esotropia. Am J Ophthalmol 1976; 89: 291-9.

4 Helveston EM, Ellis FD, Patterson JH, Weber J. Augmented recession of the medical recti. Ophthalmology (Rochester) 1978; 85: $507-11$

5 Lee DA, Dyer LA. Bilateral medial rectus muscle recession and lateral rectus muscle resection in the treatment of congenital esotropia. Am J Ophthalmol 1983; 95: 528-35.

6 Helveston EM, Ellis FD, Schott J, et al. Surgical treatment of congenital esotropia. Am J Ophthalmol 1983; 96: 218-28.

7 Kushner BJ, Morton GV. A randomized comparison of surgical procedures for infantile esotropia. Am J Ophthalmol 1984; 98: 50-61.
8 Bartlcy GB, Dyer JA, Ilstrup M. Characteristics of recessionresection and bimedial recession for childhood esotropia. Arch Ophthalmol 1985; 103: 19()-5.

9 Hess JB, Calhoun JH. A new rationale for the management of large angle esotropia. J Pediatr Ophthalmol Strabismus 1979; 16: 345-8.

10 Pricto-Diaz J. Large bilateral medial rectus recession in carly csotropia with bilateral limitation of abduction. $J$ Pediatr Ophthalmol Strabismus 1980; 17: 101-5.

11 Mittleman D, Folk ER. The surgical treatment of undercorrected esotropia: an evaluation of the effect of recession of the medial rectus muscle $13.5 \mathrm{~mm}$ from the limbus. Ophthalmology (Rochester) 1975; 79: 738-44.

12 Szmyd SM, Nelson LB, Calhoun JH, Spratt C. Large bimedial rectus recessions in congenital esotropia. Br J Ophthalmol 1985; 69: $271-4$.

13 Hiles DA, Watson BA, Biglan AW. Characteristics of infantile esotropia following early bimedial rectus recession. Arch Ophthalmol 1980; 98: 697-703.

14 Kraft SP, Scott WE. Surgery for congenital esotropia-an age comparison study. J Pediatr Ophthalmol Strabismus 1984; 21: 57-68.

15 Hirsch CR, Scott WE. Surgical treatment of large angle congenital csotropia. Invest Ophthalmol Vis Sci 1984; 25: 73 (abstr).

16 Bateman JB, Parks MM, Wheeler N. Discriminant analysis of congenital esotropia surgery. Ophthalmology (Rochester) 1983; 96: 1146-53.

17 Freeley DA, Nelson LB, Calhoun JH. Recurrent esotropia following early successful surgical correction of congenital esotropia. J Pediatr Ophthalmol Strabismus 1983; 20: 68-71.

Accepted for publication 8 July 1986. 